\title{
Architecture and expression of the Nfatc1 gene in lymphocytes
}

\section{Ronald Rudolf ${ }^{1 \dagger}$, Rhoda Busch ${ }^{1+}$, Amiya K. Patra ${ }^{1}$, Khalid Muhammad $^{1}$, Andris Avots $^{1}$, Jean-Christophe Andrau ${ }^{2}$, Stefan Klein-Hessling ${ }^{1}$ and Edgar Serfling ${ }^{1}$ *}

' Department of Molecular Pathology, Comprehensive Cancer Center Mainfranken, Institute of Pathology, University of Würzburg, Würzburg, Germany

${ }^{2}$ Centre d'Immunologie de Marseille-Luminy, Universite Aix-Marseille, Marseille, France

\section{Edited by:}

Ananda L. Roy, Tufts University School of Medicine, USA

Reviewed by:

John D. Colgan, University of lowa, USA

James Hagman, National Jewish Health, USA

\section{${ }^{*}$ Correspondence:}

Edgar Serfling, Department of

Molecular Pathology, Institute of

Pathology, University of Würzburg,

Josef-Schneider-Str. 2, Würzburg

D-97080, Germany

e-mail: serfling.e@mail.

uni-wuerzburg.de

${ }^{\dagger}$ Ronald Rudolf and Rhoda Busch have contributed equally to this work.
In lymphocytes, the three NFAT factors NFATc1 (also designated as NFAT2), NFATc2 (NFAT1), and NFATc3 (NFAT4 or NFATx) are expressed and are the targets of immune receptor signals, which lead to a rapid rise of intracellular $\mathrm{Ca}^{++}$, the activation of phosphatase calcineurin, and to the activation of cytosolic NFATc proteins. In addition to rapid activation of NFAT factors, immune receptor signals lead to accumulation of the short NFATc1/ $\alpha$ A isoform in lymphocytes which controls their proliferation and survival. In this mini-review, we summarize our current knowledge on the structure and transcription of the Nfatc 1 gene in lymphocytes, which is controlled by two promoters, two poly A addition sites and a remote downstream enhancer. The Nfatc 1 gene resembles numerous primary response genes (PRGs) induced by LPS in macrophages. Similar to the PRG promoters, the Nfatc1 promoter region is organized in CpG islands, forms DNase I hypersensitive sites, and is marked by histone tail modifications before induction. By studying gene induction in lymphocytes in detail, it will be important to elucidate whether the properties of the Nfatc1 induction are not only typical for the Nfatc1 gene but also for other transcription factor genes expressed in lymphocytes.

Keywords: chromatin, induction, lymphocytes, Nfatc1, transcription

\section{INTRODUCTION}

In peripheral B lymphocytes, the NFATc factors NFATc1, c2, and c3 are the final targets of B cell receptor (BCR)-mediated activation, and inhibiting their induction by the immunosuppressant Cyclosporin A (CsA) abrogates the antigen-induced proliferation of B cells (1). In freshly isolated (naive) splenic B cells according to the number of RNA reads in RNA Seq assays, 10 -fold more transcripts were detected for the $\mathrm{Nfatcl}$ and $\mathrm{Nfatc3}$ genes than for the Nfatc2 gene. BCR signals increase the transcription of the $\mathrm{Nfatcl}$ gene, but not of the Nfatc2 and Nfatc3 genes (Muhammad et al., submitted). Although all three NFATc transcription factors (TFs) bind to similar DNA motifs and transactivate the promoters of numerous genes in transfection studies, inactivating the individual Nfatc genes in mice resulted in quite diverging phenotypes. Whereas inactivation of the $\mathrm{Nfatcl}$ gene led to an early death of mice embryos $(2,3), \mathrm{Nfatc}^{-/-}$mice were born at normal Mendelian ratio but developed with age, a hyper-proliferative syndrome and elevated immune responses (4-6). These features of the $\mathrm{Nfatc2}^{-/-}$mice were found to be accelerated in mice deficient in both NFATc2 and NFATc3 (7). Ablation of NFATc1 in $\mathrm{B}$ cells led to a marked reduction in BCR-mediated proliferation and $\mathrm{Ca}^{++}$flux, increase in activation induced cell death (AICD), and defects in antibody production upon immunization, whereas opposite effects were observed for $\mathrm{Nfatc2}^{-/-} \mathrm{B}$ cells $(1,8)$.

These functional differences between NFATc1 and NFATc2 might be due to the synthesis of NFATc1/ $\alpha$ A, a short isoform of NFATc1, which lacks the C-terminal peptide of approximately 250 amino acids residues typical for most of the other NFATc proteins.
NFATc $1 / \alpha \mathrm{A}$ is the most prominent NFAT protein in effector $\mathrm{B}$ cells and is able to rescue B cells from early cell death (1).

\section{STRUCTURE OF THE Nfatc1 GENE}

The genes encoding NFATc1 in mouse and man consist of 11 exons and span approximately 110 and $134 \mathrm{~kb}$ DNA, respectively. Due to the existence of two promoters, two poly A sites and alternate splicing events, six NFATc1 RNAs, and proteins are generated in peripheral lymphocytes (9-11) (Figure 1A). The two Nfatcl promoters, $\mathrm{P} 1$ and $\mathrm{P} 2$, show the typical features of eukaryotic promoters. They are highly conserved between mouse and man over 800 bp (P1) or 100 bp (P2) DNA and form DNase I hypersensitive chromatin sites. Both promoters are organized in $\mathrm{CpG}$ islands. While in peripheral blood lymphocytes, in Jurkat $\mathrm{T}$ cells, and in other lymphoid cell lines in which NFATcl is expressed the DNA of promoter islands is de-methylated, inactivation of human NFATC1 gene in several Hodgkin's lymphoma cells lines is correlated with the methylation of all $\mathrm{CpG}$ dinucleotides within the P1 promoter (12).

The inducible P1 promoter of $800 \mathrm{bp}$ can be divided into two DNA "homology blocks" (10) of approximately 250 bp DNA, which harbor DNA binding motifs for Sp1 at their termini. Sp1 binding is known to protect $\mathrm{CpG}$ islands from DNA methylation $(19,20)$, and the relatively weak binding of Sp1 to these P1 sites in Hodgkin's lymphoma cells in which the promoter is suppressed led us to speculate that they could function as "road blocks" to prevent the methylation of P1 DNA in effector lymphocytes (12) [but see also Ref. (21) and below for the function of 


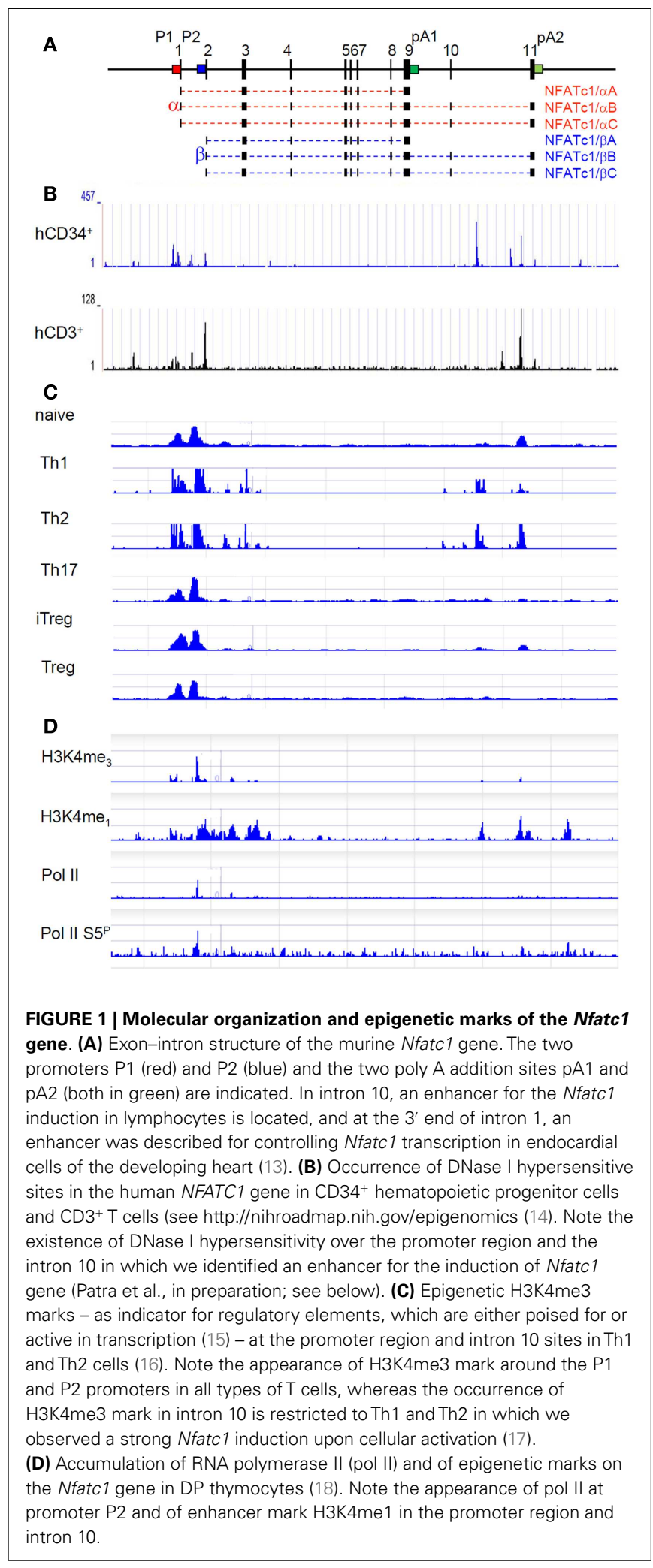

$\mathrm{Sp} 1$ in the control of primary response promoters]. The TF binding motifs within each block of homology represent composite sites for the inducible binding of Creb/Fos/ATF and NF- $\mathrm{B} / \mathrm{NFAT}$ factors. When used as probes in electrophoretic band shift assays

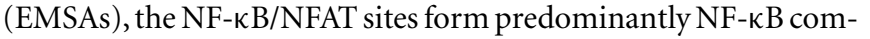
plexes with proteins from activated $\mathrm{T}$ and $\mathrm{B}$ cells. However, under conditions of high nuclear NFAT levels these sites can also be bound by NFAT. Together with the two NFAT sites within the distal block of homology, which are arranged in tandem, they enable strong binding of NFAT factors to the P1 promoter (9). This contributes to the NFATc1-mediated auto-regulation of P1-directed $N f a t c 1$ transcription, which keeps high levels of NFATc1 for days under persistent immune receptor stimulation (11).

In spite of the tight assembly of TF binding sites within the P1 promoter, when transfected into EL-4 thymoma cells, P1-directed luciferase reporter constructs showed a poor induction, which differs markedly from the induction of endogenous $N f a t c 1$ gene (9). Instead of being induced as the endogenous $\mathrm{Nfatcl}$ gene by the phorbol ester TPA and the $\mathrm{Ca}^{++}$-ionophore ionomycin (which mimic immune receptor signals), inducers of protein kinase A, such as forskolin, led in combination with ionomycin to the strongest induction of P1 in EL-4 thymoma cells (9).

These functional studies on the induction of Nfatc1 P1 promoter led us to conclude that not all sequence elements controlling the induction of the $N f a t c 1$ gene in lymphocytes are part of its promoter region. Whereas fusion of more upstream DNA to the highly conserved P1 region of approximately $800 \mathrm{bp}$ did not result in any increase in promoter induction, fusion of a 1-kb DNA fragment from the central region of intron 1 of the $N f a t c 1$ gene to P1 enhanced its overall activity fourfold to fivefold, but did not affect its induction mode (9). However, when we inserted an element from intron 10 of the $N f a t c 1$ gene into a luciferase construct directed by the P1 (or P2) promoter, we observed both a strong increase in promoter induction and a mode of induction similar to the endogenous $N f a t c l$ gene. These findings suggest that an enhancer for the optimal induction of $N f a t c 1$ gene is located in intron 10, which supports $\mathrm{Nfatcl}$ induction in lymphocytes (Patra et al., in preparation).

In Figures 1B,C, mapping studies of DNase I hypersensitive sites in human $\mathrm{CD}_{3} 4^{+}$lymphoid progenitor cells and $\mathrm{CD} 3^{+} \mathrm{T}$ cells and of $\mathrm{H} 3 \mathrm{~K} 4 \mathrm{me} 3$ mark in various subsets of murine T cells are presented for the $N f a t c 1$ gene. They show that, in addition to the promoter region, both DNase I hypersensitive chromatin sites and H3K4me3 marks were mapped within intron 10 of Nfatc1. The distal intron 10 site was found to be marked by H3K4me1 and H3K4me3 modifications (see Figures 1C,D), and the enrichment of H3K4me3 was identified as a feature of active enhancers in $\mathrm{T}$ cells (22). And indeed, we determined this site (designated as E2) as an enhancer element that supports the induction of P1 and $\mathrm{P} 2$ promoters in lymphocytes (Patra et al., in preparation). Interestingly, E2 appears to be less active (or inactive) in Th17 cells, in thymus-derived regulatory $\mathrm{T}$ cells (Treg), and in induced Treg (iTreg) in which we observed a weak $N f a t c 1$ induction (17).

In resting $\mathrm{CD}^{+}{ }^{+} \mathrm{T}$ cells and DP thymocytes in which $\mathrm{Nfatcl}$ is poorly expressed, the (P2) promoter region of the $\mathrm{Nfatcl}$ gene shows characteristics of a "transcription initiation platform." In ChIP-Seq assays using DP thymocytes, the RNA polymerase II (pol II) was found to be bound at P2 (and not at P1), whereas the enhancer mark H3K4me1 was detected over the entire promoter region and several intron 10 sites (Figure 1D) (18). However, when 
ChIP assays were performed for H3K27ac, a mark for active - and not only poised - enhancers (23), only a peak over the central intron 10 enhancer segment E2 appeared in double-negative (DN) thymocytes (Andrau, in preparation) in which the $N f a t c l$ gene is expressed more robustly than in DP thymocytes (17).

\section{Nfatc1 EXPRESSION IN PERIPHERAL B CELLS}

When splenic B cells are induced by $\alpha-\operatorname{IgM}$ for $24 \mathrm{~h}$ ex vivo, the predominant synthesis of short NFATc1 isoform NFATc1/ $\alpha$ A is observed $(1,17)$. While in Western blots using whole $\mathrm{B}$ cell protein a strong, more than 50 -fold induction of NFATc1/ $\alpha$ A protein is detected, in real time PCR assays measuring the levels of $N f a t c 1 / \alpha A$ RNA a 5- to 10 -fold increase was observed, and in recent RNA Seq assays, high levels of NFATc1 RNA were found in non-stimulated primary splenic B cells, which are not reflected at the protein level. These observations suggest the existence of both transcriptional and post-transcriptional control mechanisms, which shape the appearance of NFATc1 protein(s) upon B (and T) cell induction.

To study the expression of $N f a t c 1$ gene at the transcriptional level in vivo, we generated a BAC transgenic ( $\mathrm{tg}$ ) mouse line, which expresses an Egfp reporter gene under the control of the entire Nfatcl locus (17). Within the BAC construct, the Egfp reporter replaces exon 3 of the $N f a t c 1$ gene followed by a SV40 poly A addition signal, which gives rise to short chimeric Nfatc1/Egfp RNAs and proteins. Therefore, the $N f a t c 1 / E g f p$ transcripts are generated under the control of all regulatory elements of the Nfatcl gene, including both promoters and the downstream enhancer. However, the post-transcriptional mechanisms leading to NFATc1/ $\alpha \mathrm{A}$ protein differ certainly between "normal" $N f a t c 1$ and $N f a t c 1 / E g f p$ transcripts. Thus, in lymphocytes of tg Nfatcl/Egfp mice, the expression of chimeric Nfatcl/Egfp tg should reflect the transcription of $N f a t c 1$ locus, but not the expression of NFATc1 proteins.

In tg $N f a t c 1 / E g f p$ mice, the $N f a t c 1$ gene is expressed as early as in DN thymocytes and in naïve resting $\mathrm{T}$ and $\mathrm{B}$ cells of peripheral lymphoid organs. Although before the induction of pre-T cell receptor at the transition of DN3 to DN4 thymocytes, NFATc1 $\alpha$ isoforms are not generated and, therefore, the $\mathrm{P} 1$ promoter is less active (or inactive), the $N$ fatcl gene appears to be transcribed at a relatively high level in DN thymocytes lacking any immune receptor (Patra et al., in preparation). This appears also to be the case in naïve and resting $\mathrm{T}$ and $\mathrm{B}$ lymphocytes. Thus, similar to other TF genes encoding Fos, Jun, Egr, ATF, and further TF factors, which harbor CpG islands in their promoters, the $N f a t c 1$ gene seems to belong to the group of primary response genes (PRGs) that show a moderate 5- to 10-fold induction upon cellular stimulation. Contrary to secondary response genes (SRGs), which are often induced more than 100-fold, PRGs appear to be organized in an "open" chromatin, which is poised for transcription or transcribed at a low level $(24,25)$.

To a large part, our current view on the regulation of inducible genes bases on studies about LPS-mediated gene induction in macrophages $(21,26)$, see also (27) and (24). Previous approaches on the knock down of components of SWI/SNF nucleosome remodeling complexes in macrophages showed that in contrast to the SWI/SNF-dependent induction of SRGs, the LPS-mediated induction of PRGs is independent of SWI/SNF (28). Similar to promoters of many house-keeping genes, which are also organized in CpG islands, PRG promoters exhibit constitutively active chromatin with unstable nucleosomes, which form constitutive DNase I hypersensitive regions (26). Before induction, they are associated with the initiating version of pol II phosphorylated at "Ser5" within their C-terminal domain (CTD), and with Sp1, which helps to recruit pol II. But contrary to the heat shock genes in Drosophila, which are also pre-loaded with pol II and transcribed into short RNAs (29), PRG transcripts in macrophages are elongated to fulllength transcripts, which appear to be instable and un-spliced (21). LPS stimulation, however, which often leads to binding of NF-кB to the promoters of PRGs results in the phosphorylation of pol II at position S2 within its CTD repeats and the generation of stable RNAs, which are spliced and processed $(21,26)$.

The architecture of the $N f a t c 1$ promoter region and its induction is similar, but not in all aspects, to PRG promoters and their induction in macrophages. In lymphocytes, induction of the Nfatcl gene is controlled predominantly by immune receptor signals but not by LPS [or other co-stimulatory signals; see Ref. (1)]. The Nfatcl promoter region is organized in CpG islands, forms DNase I hypersensitive sites, and is bound by Sp1 [and CREB, which controls activity-dependent PRG regulation in neurons (30)] prior to its induction by NF- $\kappa$ B. However, induction of the $\mathrm{Nfatc1}$ promoter differs significantly from that of PRG promoters in macrophages. In contrast to PRGs (31) and similar to the "inducible house-keeping" Nfkbia gene (21), the Nfatcl gene is efficiently transcribed in lymphocytes prior to the appearance of stable, spliced transcripts in response to receptor signals. These transcripts, however, remain un-translated (Muhammad et al., in preparation.).

\section{SUMMARY AND IMPLICATIONS}

The immune receptor-mediated induction of NFATc1 TFs in peripheral lymphocytes can be divided in two events: (i) the rapid nuclear transport and activation of pre-formed cytosolic NFATc proteins, and (ii) the massive transcriptional and posttranscriptional induction of NFATc $1 / \alpha \mathrm{A}$, a short NFATc1 protein, which differs in many properties from other NFATc proteins (10). Although the induction of the $N f a t c 1$ gene leading to NFATcl/ $\alpha \mathrm{A}$ in lymphocytes resembles the LPS-mediated induction of PRGs in macrophages, it appears to differ from the induction of many PRGs by (i) its high constitutive transcription into spliced transcripts and (ii) its enhancer-mediated control. While the molecular details of these events remain to be elucidated, it will be important to investigate whether the properties of Nfatcl induction are specific for the $N f a t c 1$ gene or a property of immune receptormediated induction of many TF genes in lymphocytes. In any way, the detailed knowledge of molecular mechanisms controlling the induction of NFATc1 in lymphocytes could pave the way to interfere with its induction, which controls numerous aspects of adaptive immunity.

\section{ACKNOWLEDGMENT}

This publication was funded by the German Research Foundation (DFG) and the University of Wuerzburg in the funding programme Open Access Publishing. 


\section{REFERENCES}

1. Bhattacharyya S, Deb J, Patra AK, Thuy Pham DA, Chen W, Vaeth M, et al. NFATcl affects mouse splenic B cell function by controlling the calcineurin NFAT signaling network. J Exp Med (2011) 208:823-39. doi:10.1084/jem. 20100945

2. de la Pompa JL, Timmerman LA, Takimoto H, Yoshida H, Elia AJ, Samper E, et al. Role of the NF-ATc transcription factor in morphogenesis of cardiac valves and septum. Nature (1998) 392:182-6. doi:10.1038/32419

3. Ranger AM, Grusby MJ, Hodge MR, Gravallese EM, de la Brousse FC, Hoey T, et al. The transcription factor NF-ATc is essential for cardiac valve formation. Nature (1998) 392:186-90. doi:10.1038/32426

4. Hodge MR, Ranger AM, Charles de la Brousse F, Hoey T, Grusby MJ, Glimcher LH. Hyperproliferation and dysregulation of IL-4 expression in NFATp-deficient mice. Immunity (1996) 4:397-405. doi:10.1016/S1074-7613(00) 80253-8

5. Schuh K, Kneitz B, Heyer J, Bommhardt U, Jankevics E, Berberich-Siebelt F, et al. Retarded thymic involution and massive germinal center formation in NF-ATp-deficient mice. Eur J Immunol (1998) 28:2456-66. doi:10.1002/(SICI) 1521-4141(199808)28:08<2456::AID-IMMU2456>3.0.CO;2-9

6. Xanthoudakis S, Viola JP, Shaw KT, Luo C, Wallace JD, Bozza PT, et al. An enhanced immune response in mice lacking the transcription factor NFAT1. Science (1996) 272:892-5. doi:10.1126/science.272.5263.892

7. Ranger AM, Oukka M, Rengarajan J, Glimcher LH. Inhibitory function of two NFAT family members in lymphoid homeostasis and Th2 development. Immunity (1998) 9:627-35. doi:10.1016/S1074-7613(00)80660-3

8. Samanta DN, Palmetshofer A, Marinkovic D, Wirth T, Serfling E, Nitschke L. $\mathrm{B}$ cell hyperresponsiveness and expansion of mature follicular B cells but not of marginal zone B cells in NFATc2/c3 double-deficient mice. J Immunol (2005) 174:4797-802.

9. Chuvpilo S, Jankevics E, Tyrsin D, Akimzhanov A, Moroz D, Jha MK, et al. Autoregulation of NFATcl/A expression facilitates effector T cells to escape from rapid apoptosis. Immunity (2002) 16:881-95. doi:10.1016/S1074-7613(02) 00329-1

10. Serfling E, Avots A, Klein-Hessling S, Rudolf R, Vaeth M, Berberich-Siebelt F. NFATc1/alphaA: the other face of NFAT factors in lymphocytes. Cell Commun Signal (2012) 10:16. doi:10.1186/1478-811X-10-16

11. Serfling E, Chuvpilo S, Liu J, Hofer T, Palmetshofer A. NFATc1 autoregulation: a crucial step for cell-fate determination. Trends Immunol (2006) 27:461-9. doi:10.1016/j.it.2006.08.005

12. Akimzhanov A, Krenacs L, Schlegel T, Klein-Hessling S, Bagdi E, Stelkovics E, et al. Epigenetic changes and suppression of the nuclear factor of activated T cell 1 (NFATC1) promoter in human lymphomas with defects in immunoreceptor signaling. Am J Pathol (2008) 172:215-24. doi:10.2353/ajpath.2008. 070294

13. Zhou B, Wu B, Tompkins KL, Boyer KL, Grindley JC, Baldwin HS. Characterization of Nfatcl regulation identifies an enhancer required for gene expression that is specific to pro-valve endocardial cells in the developing heart. Development (2005) 132:1137-46. doi:10.1242/dev.01640

14. Bernstein BE, Stamatoyannopoulos JA, Costello JF, Ren B, Milosavljevic A, Meissner A, et al. The NIH Roadmap Epigenomics Mapping Consortium. Nat Biotechnol (2010) 28:1045-8. doi:10.1038/nbt1010-1045

15. Santos-Rosa H, Schneider R, Bannister AJ, Sherriff J, Bernstein BE, Emre NC, et al. Active genes are tri-methylated at K4 of histone H3. Nature (2002) 419:407-11. doi:10.1038/nature01080

16. Wei G, Wei L, Zhu J, Zang C, Hu-Li J, Yao Z, et al. Global mapping of $\mathrm{H} 3 \mathrm{~K} 4 \mathrm{me} 3$ and $\mathrm{H} 3 \mathrm{~K} 27 \mathrm{me} 3$ reveals specificity and plasticity in lineage fate determination of differentiating CD4+ T cells. Immunity (2009) 30:155-67. doi:10.1016/j.immuni.2008.12.009

17. Hock M, Vaeth M, Rudolf R, Patra AK, Pham DA, Muhammad K, et al. NFATc1 induction in peripheral T and B lymphocytes. J Immunol (2013) 190:2345-54. doi:10.4049/jimmunol.1201591
18. Koch F, Fenouil R, Gut M, Cauchy P, Albert TK, Zacarias-Cabeza J, et al. Transcription initiation platforms and GTF recruitment at tissue-specific enhancers and promoters. Nat Struct Mol Biol (2011) 18:956-63. doi:10.1038/nsmb.2085

19. Brandeis M, Frank D, Keshet I, Siegfried Z, Mendelsohn M, Nemes A, et al. Spl elements protect a CpG island from de novo methylation. Nature (1994) 371:435-8. doi:10.1038/371435a0

20. Macleod D, Charlton J, Mullins J, Bird AP. Spl sites in the mouse aprt gene promoter are required to prevent methylation of the CpG island. Genes Dev (1994) 8:2282-92. doi:10.1101/gad.8.19.2282

21. Hargreaves DC, Horng T, Medzhitov R. Control of inducible gene expression by signal-dependent transcriptional elongation. Cell (2009) 138:129-45. doi:10.1016/j.cell.2009.05.047

22. Pekowska A, Benoukraf T, Zacarias-Cabeza J, Belhocine M, Koch F, Holota H, et al. H3K4 tri-methylation provides an epigenetic signature of active enhancers. EMBO J (2011) 30:4198-210. doi:10.1038/emboj.2011.295

23. Creyghton MP, Cheng AW, Welstead GG, Kooistra T, Carey BW, Steine EJ, et al. Histone $\mathrm{H} 3 \mathrm{~K} 27 \mathrm{ac}$ separates active from poised enhancers and predicts developmental state. Proc Natl Acad Sci U S A (2010) 107:21931-6. doi:10.1073/pnas.1016071107

24. Fowler T, Sen R, Roy AL. Regulation of primary response genes. Mol Cell (2011) 44:348-60. doi:10.1016/j.molcel.2011.09.014

25. Smale ST. Transcriptional regulation in the innate immune system. Curr Opin Immunol (2012) 24:51-7. doi:10.1016/j.coi.2011.12.008

26. Ramirez-Carrozzi VR, Braas D, Bhatt DM, Cheng CS, Hong C, Doty KR, et al. A unifying model for the selective regulation of inducible transcription by CpG islands and nucleosome remodeling. Cell (2009) 138:114-28. doi:10.1016/j.cell.2009.04.020

27. Singh H. Teeing up transcription on CpG islands. Cell (2009) 138:14-6. doi:10.1016/j.cell.2009.06.028

28. Ramirez-Carrozzi VR, Nazarian AA, Li CC, Gore SL, Sridharan R, Imbalzano AN, et al. Selective and antagonistic functions of SWI/SNF and Mi-2beta nucleosome remodeling complexes during an inflammatory response. Genes Dev (2006) 20:282-96. doi:10.1101/gad.1383206

29. Saunders A, Core LJ, Lis JT. Breaking barriers to transcription elongation. Nat Rev Mol Cell Biol (2006) 7:557-67. doi:10.1038/nrm1981

30. Knoll B, Nordheim A. Functional versatility of transcription factors in the nervous system: the SRF paradigm. Trends Neurosci (2009) 32:432-42. doi:10.1016/ j.tins.2009.05.004

31. Bhatt DM, Pandya-Jones A, Tong A-J, Barozzi I, Lissner M, Natoli G, et al. Transcript dynamics of pro-inflammatory genes uncovered by RNA-Seq analysis of subcellular RNA fractions. Cell (2012) 150:279-90. doi:10.1016/j.cell.2012. 05.043

Conflict of Interest Statement: The authors declare that the research was conducted in the absence of any commercial or financial relationships that could be construed as a potential conflict of interest.

Received: 24 October 2013; accepted: 15 January 2014; published online: 03 February 2014.

Citation: Rudolf R, Busch R, Patra AK, Muhammad K, Avots A, Andrau J-C, KleinHessling $S$ and Serfling $E$ (2014) Architecture and expression of the Nfatcl gene in lymphocytes. Front. Immunol. 5:21. doi: 10.3389/fimmu.2014.00021

This article was submitted to B Cell Biology, a section of the journal Frontiers in Immunology.

Copyright (ㄷ 2014 Rudolf, Busch, Patra, Muhammad, Avots, Andrau, Klein-Hessling and Serfling. This is an open-access article distributed under the terms of the Creative Commons Attribution License (CC BY). The use, distribution or reproduction in other forums is permitted, provided the original author(s) or licensor are credited and that the original publication in this journal is cited, in accordance with accepted academic practice. No use, distribution or reproduction is permitted which does not comply with these terms. 